\title{
CRITHIDIA RICARDOI SP. N. A NEW SPECIES OF TRYPANOSOMATIDAE ISOLATED FROM CULEX SALTANENSIS DYAR, 1928 (DIPTERA: CULICIDAE)
}

\author{
ALEXANDER SIBAJEV+; RAQUEL S. PACHECO*; MAURÍLIO J. SOARES**; \\ ELISA CUPOLILLO*; ÁLVARO BERTHO DOS SANTOS \& HOOMAN MOMEN*
}

\author{
Departamento de Protozoologia *Departamento de Bioquimica e Biologia Molecular \\ **Departamento de Ultraestrutura e Biologia Celular, Instituto Oswaldo Cruz, Av. Brasil 4365, $21045-900$ \\ Rio de Janeiro, RJ, Brasil
}

A flagellate trypanosomatid was isolated in culture from the digestive tract of the mosquito Culex saltanensis Dyar, 1928. It grows exuberantly in liver infusion in the form of epimastigotes and choanomastigotes typical of the genus $\mathrm{Crith}$ idia. The trypanosomatid was compared to $\mathrm{C}$. deanei, C. fasciculata, C. luciliae, C. oncopelti and C. guilhermei. The techniques used for comparison were electron transmission microscopy, isoenzymes and $k D N A$ restriction profiles. No endosymbionts were found at electron microscopy. Results for the biochemical methods employed indicate that the trypanosomatid isolated from C. saltanensis is a new species of Crithidia. The name C. ricardoi $s p$. n. is proposed for this new species.

\footnotetext{
Key words: Crithidia ricardoi sp. n. - trypanosomatidae - Culex saltanensis - kDNA - isoenzymes electron microscopy - cell sorting
}

Trypanosomatids parasitizing insects are very common. They include the subgenus Leptomonas, Herpetomonas, Crithidia, Blastocrithidia and Rynchoidomonas. Under the genus Crithidia Léger, 1902 many species or varieties have been described as parasites of insects (Wallace, 1966). In order to formalize new findings, biochemical analysis, as suggested by Wallace et al. (1983), should be used to give the appropriate taxonomic evaluation of the differences found. To correctly identify the flagellate isolated, five other Crithidia were used for comparison. Species used were isolated from Diptera and Hemiptera. C. fasciculata Léger, 1902 is the type-species for the genus Crithidia. It was isolated from the mosquito Anopheles maculipennis. $C$. luciliae (Strickland, 1911) Wallace \& Clark, 1959 was isolated from Phaenicia sericala, a Calliphoridae. C. oncopelti (Noguchi \& Tilden, 1926) Lwoff \& Lwoff, 1931 was described as originating either from the milkweed Asclepias syriaca or from the milkweed bug Oncopeltus fasciatus. Posterior serological studies concluded that $C$. oncopelti did not come from a

Financial support was provided by CAPES and FAPERJ. ${ }^{+}$Current adress: Departamento de Bioquímica e Biologia Molecular.

Received 5 January 1993.

Accepted 9 September 1993. plant or hemiptera and its origin remains unknown (McGhee \& Hanson, 1968; McGhee et al., 1969). C. deanei Carvalho, 1973 was isolated from an insectivorous hemiptera Zelus leucogramus. Whether $C$. deanei is actually an intestinal parasite of $Z$. leucogramus or it was accidentally ingested within one of its insect prey is a fact to be clarified (Carvalho \& Deane, 1974; Wallace et al., 1983). C. guilhermei Soares et al., 1986 was isolated from the Calliphoridae fly Phaenicia cuprina.

The mosquito found infected by C. ricardoi was Culex (Culex) saltanensis Dyar, 1928, a highly ornitophilic mosquito species. It is the natural vector of Plasmodium juxtanucleare, an avian malaria parasite (Lourenço-deOliveira, 1991) at Granjas Calábria, Jacarepaguá, Rio de Janeiro, Brazil. This mosquito has a wide geographic distribution in South America being recorded in Argentina (Salta Province, its type-locality), Venezuela, Panama and in Brazil (States of São Paulo, Rio de Janeiro and Bahia).

\section{MATERIALS AND METHODS}

The digestive tracts of $C$. saltanensis specimens caught at Granjas Calábria $\left(23^{\circ} 00^{\prime} \mathrm{S}\right.$, $43^{\circ} 26^{\prime} \mathrm{W}$ ), Rio de Janeiro, Brazil, dissected in aseptic conditions, were observed by light 
microscopy for flagellates. Positive tracts were diluted in sterile $0.9 \% \mathrm{NaCl}$ solution, inoculated in $2 \mathrm{ml}$ of NNN-LIT supplemented with $10 \%$ fetal calf serum and $100 \mathrm{U}$ penicillin. Tubes were kept at $27.5^{\circ} \mathrm{C}$ and transferred at three to four day intervals.

For the measurement at the light microscopic level, smears of 3-day-old culture forms were fixed in methanol and stained in Giemsa.

For transmission electron microscopy, 3day-old culture forms were collected by centrifugation at $1500 \mathrm{G}$ for $5 \mathrm{~min}$. The pellet was fixed, embedded and ultrathin sections observed as described in Soares et al. (1986).

Isoenzyme and kDNA analyses were made comparatively with other Crithidia species: fasciculata ATCC \# 11745, oncopelti ATCC \# 30264, deanei ATCC \# 30255, luciliae ATCC \# 14765 and guilhermei (Universidade Federal do Rio de Janeiro - UFRJ) which was used only for the kDNA analysis, jointly with the above species.

For the isoenzyme characterization, agarose gel electrophoresis was performed for 11 loci: malate dehydrogenase (MDH E.C.1.1.1.37), malic enzyme (ME E.C.1.1.1.40), isocitrate dehydrogenase (IDH E.C.1.1.1.42), 6-phosphogluconate dehydrogenase (6PGDHE.C.1.1.1.44), glucose-6-phosphate dehydrogenase (G6PDH E.C.1.1.1.49), phosphoglucomutase (PGM E.C.2.7.5.1), esterase (EST E.C.3.1.1.1), peptidase 1 (PEP1 E.C.3.4.11), aconitase (ACON E.C.4.2.1.3), fumarase (FUM E.C.4.2.12) as described in Momen et al. (1985). Results were used to calculate the Jaccard's coefficient of similarity (Sneath \& Sokal, 1973).

Clones were made from $0.5 \mathrm{ml}$ of two 3 -day-old $C$. ricardo $i$ isolates using a fluorescent cell sorter (Epics/Coulter). Two cloned samples of the two isolates and the isolates themselves, in a total of four samples, were comparatively analyzed with the other species of Crithidia.

Extraction and analysis of restriction enzyme profiles of kinetoplast DNA were as follows: parasites were lysed using Sarkosil and digested by Pronase at $60^{\circ} \mathrm{C}$. kDNA was collected by centrifugation, extracted by phenol/chloroform and precipitated by ethanol. Purified kDNA $(2 \mu \mathrm{g})$ was digested with the restriction enzymes MSp I, Rsa I and Hae III in appropriate buffers. The products of diges- tion were separated by electrophoresis in 5$10 \%$ linear gradient polyacrylamide gels and stained with ethidium bromide (Pacheco et al., 1990).

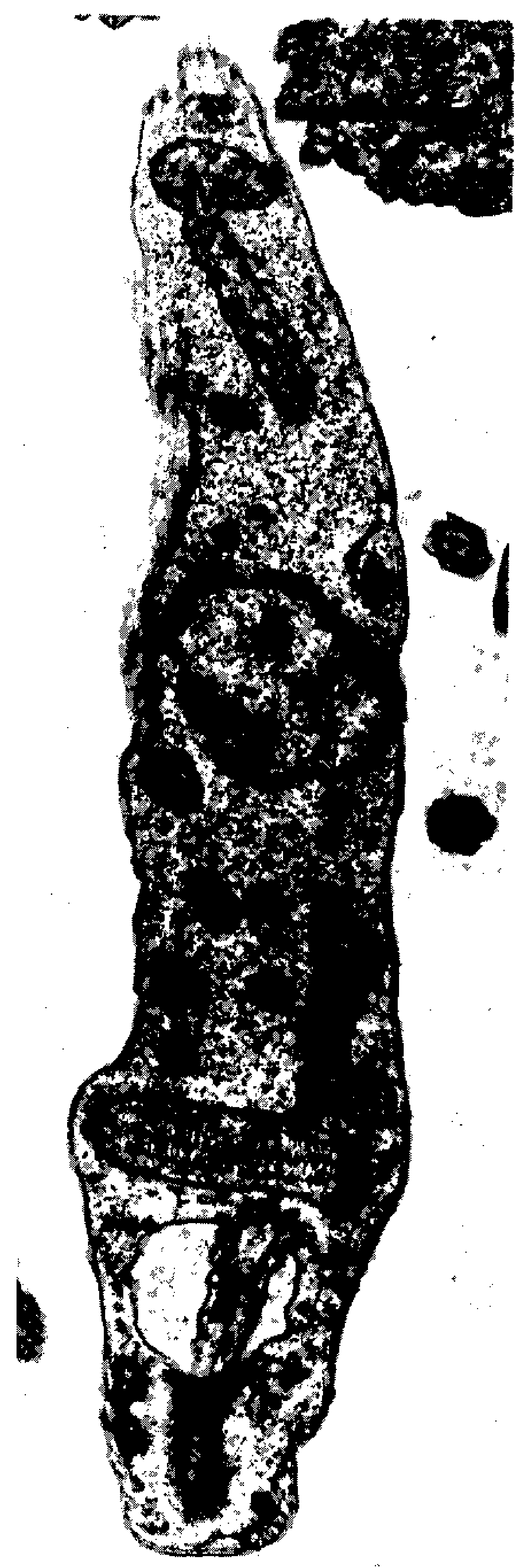

Fig. 1: transmission electron microscopy of an ultrathin section of Crithidia ricardoi sp. $n$. Longitudinal section of a parasite, showing the mitochondrion (M), nucleus $(N)$, glycosomes $(G)$, kinetoplast DNA $(\mathrm{K})$ and the flagellum (F). Bar $=1 \mu \mathrm{m}$. 
TABLE

Input data matrix of the allelic presence/absence for eleven isoenzymatic loci in five Crithidia species

\begin{tabular}{lccccccccccc}
\hline $\begin{array}{l}\text { Crithidia } \\
\text { Species/Enzymes }\end{array}$ & PGM & G6P & 6PG & GPI & ME & FUM & PEPI & EST & IDH & MDH & ACON \\
\hline C. ricardoi (c1) & 010 & 01 & 10 & 1 & 100 & 0111 & 1 & 10000 & 001 & 01110 & 10 \\
(c2) & 010 & 01 & 10 & 1 & 100 & 0111 & 1 & 10000 & 001 & 01110 & 10 \\
(c3) & 010 & 01 & 10 & 1 & 100 & 0111 & 1 & 10000 & 001 & 01110 & 10 \\
(c4) & 010 & 01 & 10 & 1 & 100 & 0111 & 1 & 10000 & 001 & 01110 & 10 \\
fasciculata & 001 & 10 & 10 & 1 & 1000 & 0111 & 1 & 01100 & 001 & 01111 & 10 \\
deanei & 010 & 01 & 10 & 1 & 110 & 1111 & 1 & 10000 & 011 & 11110 & 00 \\
oncopelti & 100 & 01 & 01 & 0 & 101 & 0110 & 0 & 00011 & 100 & 10000 & 00 \\
luciliae & 001 & 00 & 10 & 1 & 100 & 0111 & 1 & 01000 & 001 & 01111 & 01 \\
\hline
\end{tabular}

c1 - clone of isolate 1 of Crithidia ricardoi; $\mathrm{c} 2$ - total population of isolate 1 of C. ricardoi; $\mathrm{c} 3$ - clone of isolate 2 of C. ricardoi; $\mathrm{c} 4$ - total population of isolate 2 of $C$. ricardoi.

\section{RESULTS}

\section{Crithidia ricardoi $\mathrm{sp} . \mathrm{n}$.}

Type host: Culex (Culex) saltanensis Dyar, 1928 (Márcia Gonçalves de Castro ident.)

Location in host: gut, mainly hindgut.

Location: Granjas Calábria $\left(23^{\circ} 00^{\prime} \mathrm{S}, 43^{\circ}\right.$ 26'W), Jacarepaguá, Rio de Janeiro, Brazil.

DIAGNOSIS: $C$. ricardoi: total length: 9.5 to $18.0 \mu \mathrm{m}$ (average: $13.0 \mu \mathrm{m}$ ); body length: 5.0 to $12.0 \mu \mathrm{m}$ (avg $7.0 \mu \mathrm{m}$ ); free flagellum: 4.5 to $10.0 \mu \mathrm{m}$ (avg $5.0 \mu \mathrm{m}$ ); body width: 1.5 to $3.0 \mu \mathrm{m}$ (avg $1.5 \mu \mathrm{m}$ ); nucleus width: 1.0 to $1.5 \mu \mathrm{m}$ (avg $1.0 \mu \mathrm{m}) . \mathrm{N}=50$ cells.

Giemsa-stained and electron microscopy prepared cells showed a choanomastigote form for C. ricardoi sp. n. (Fig. 1).

C. ricardoi $\mathrm{sp} . \mathrm{n}$. had the same profile for five out of eleven isoenzymes with $C$. deanei (PGM, G6P, 6PG, PEPI and EST) and $C$. luciliae (6PG, ME, FUM, PEP1 and IDH). Compared to $C$. fasciculata, four isoenzymatic loci were the same (6PG, ME, PEPl and ACON). G6P was the only enzyme that exhibited similarity when compared to oncopelti. The enzyme MDH can distinguish the new isolate from all 4 other species (Table; Fig. 2).

Marked differences in the kDNA minicircle regions were observed among all the species analyzed including the new one, thus supporting the status of distinct taxon (Fig. 3). Although kDNA analyses of the new isolate had shown a more complex genotypic profile suggesting the possibility of mixture of subpopulations or mixed infection, preliminary experi- ments with two cloned populations of $C$. ricardoi revealed parental genotypic similarity in their $\mathrm{kDNA}$ restriction profile, e.g., no differences were detected among cloned and randomized populations. Two other insect trypanosomatids, Herpetomonas samuelpessoai ATCC \# 30252 and Blastocrithidia culicis (UFRJ) also displayed distinct profiles (data not shown).

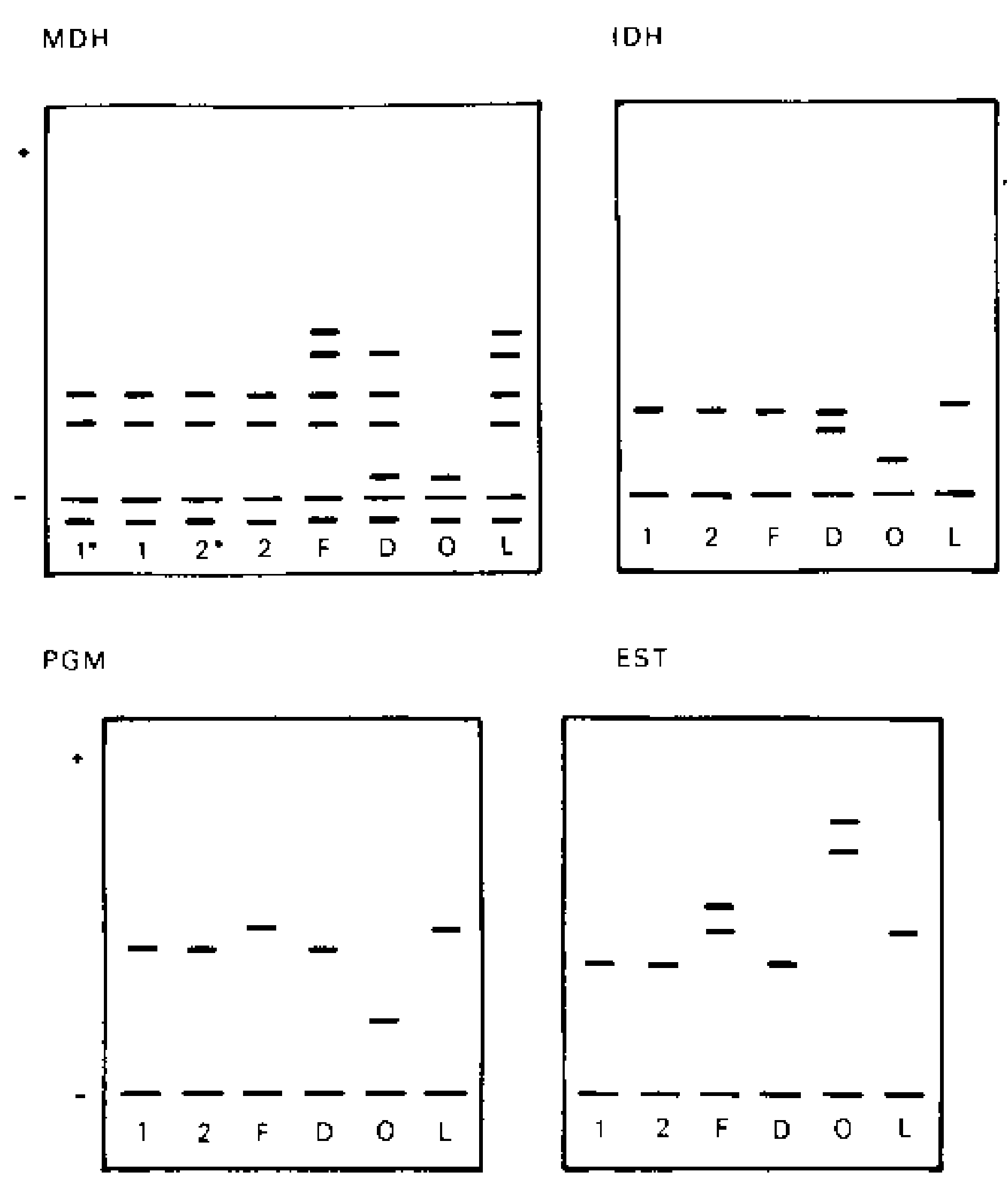

Fig. 2: diagram showing agarose électrophoresis gel profiles of isoenzymes: a - MDH (Malate Dehydrogenase); b - IDH (Isocitrate Dehydrogenase); c - PGM (Phosphoglucomutase); d - EST (Esterase). Lanes: 1 Clone of isolate 1 of Crithidia ricardoi; 2 - Total population of isolate 1 of $C$. ricardoi; 3 - Clone of isolate 2 of $C$. ricardoi; 4 - Total population of isolate 2 of $C$. ricardoi; $5-C$. fasciculata; $6-C$. deanei; $7-C$. oncopelti; 8 - C. luciliae. 

FRDLO
F R D L O
F R D L O
R G

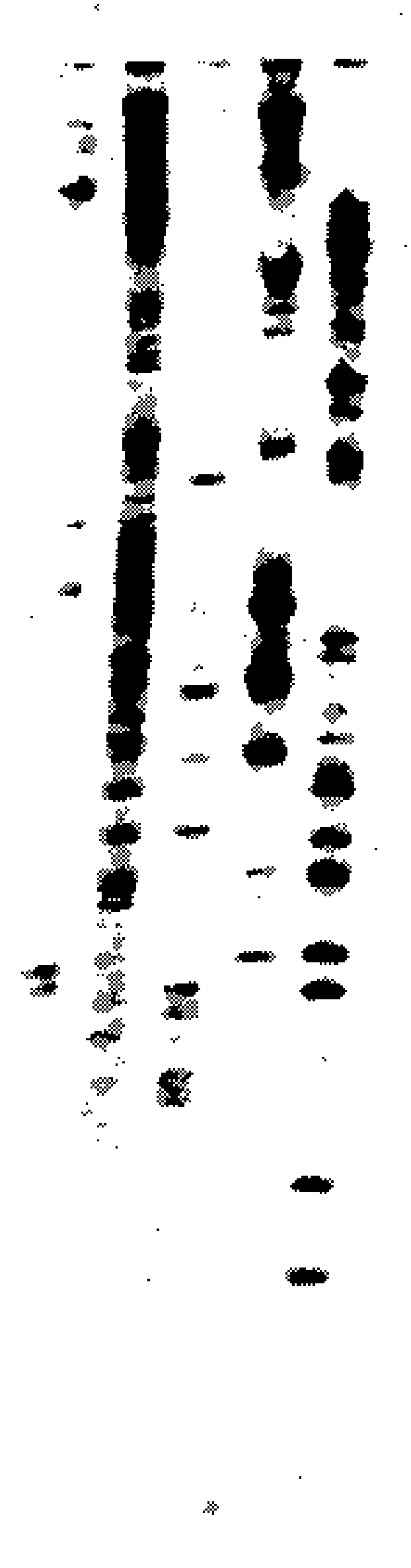

Rsa 1

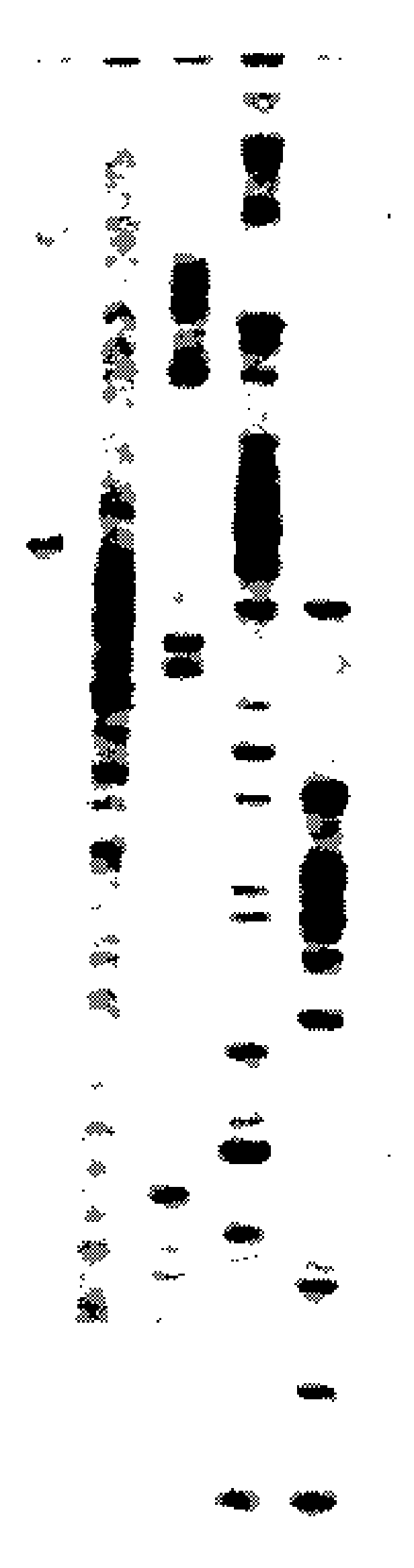

Msp I

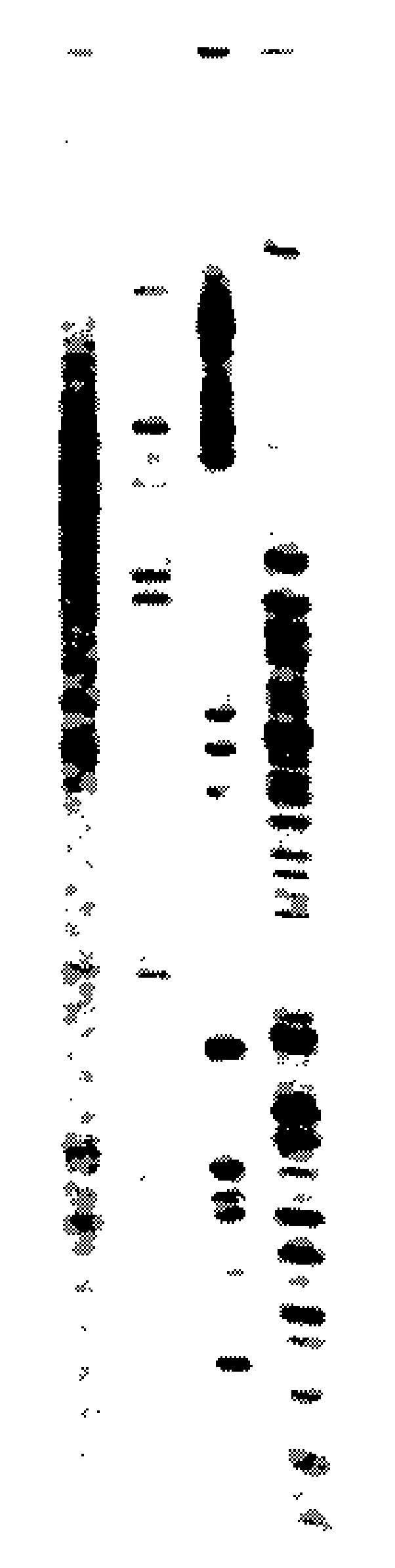

Hae III

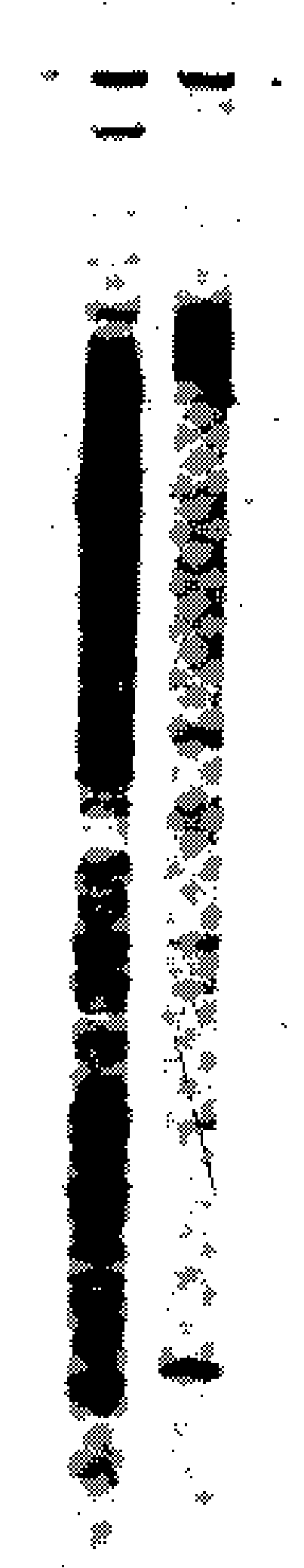

Hae III

Fig. 3: kDNA minicircle fragments of different Crithidia species after digestion with the restriction enzymes $R$ saI (A); MspI (B) and Haelll (C) in a $5-10 \%$ gradient gel.

\section{DISCUSSION}

A flagellate trypanosomatid isolated from C. saltanensis was compared with five other species of Crithidia. Three different techniques were used: electron microscopy, isoenzyme electrophoresis and KDNA restriction analysis. Although in lower trypanosomatids, electron microscopy is likely to be uninformative, due to the homogeneity of the group, we believe that detailed examination of the fine structure of new isolates can show interesting findings that may produce results of taxonomic significance.

Similarity given by Jaccard's coefficient calculated from isoenzymatic data, indicates that: (a) the samples could be divided in two major groups separating $C$. oncopelti from other crithidias by a $\mathrm{Sj}=0.24$. A Sj=0.66 separate the second group in two minor ones, the first containing C. fasciculata and C. luciliae and the second $C$. ricardoi and $C$. deanei. $\mathrm{A} \mathrm{Sj}=$ 0.85 separate fasciculata from luciliae and ricardoi from deanei; (b) the four C. ricardoi samples (two isolates and two cloned samples from them) had a $\mathrm{Sj}=1.00$ indicating total similarity (Fig. 4).

Wallace et al. (1983) pointed out that insect hosts can not be used as informative taxonomic data. It was previously believed that these parasites were narrowly limited in their host distribution and that each insect had its own peculiar parasite (names derived from insects shows this early belief). Based on host, one would expect that crithidias originating from common hosts such as Hemiptera for luciliae, oncopelti and deanei and Diptera for fasciculata and ricardoi should be grouped together in the isoenzymatic analysis. Nevertheless, $C$. oncopelti was grouped separately being the most dissimilar $(\mathrm{Sj}=0.24)$. C. luciliae grouped with $C$. fasciculata and $C$. deanei with C. ricardoi. The analysis corroborates earlier suspicions that deanei originated from infected insect prey of $Z$. leucogramus (Carvalho \& Deane, 1974). It also provides data on the eurixenic nature of the crithidias. 


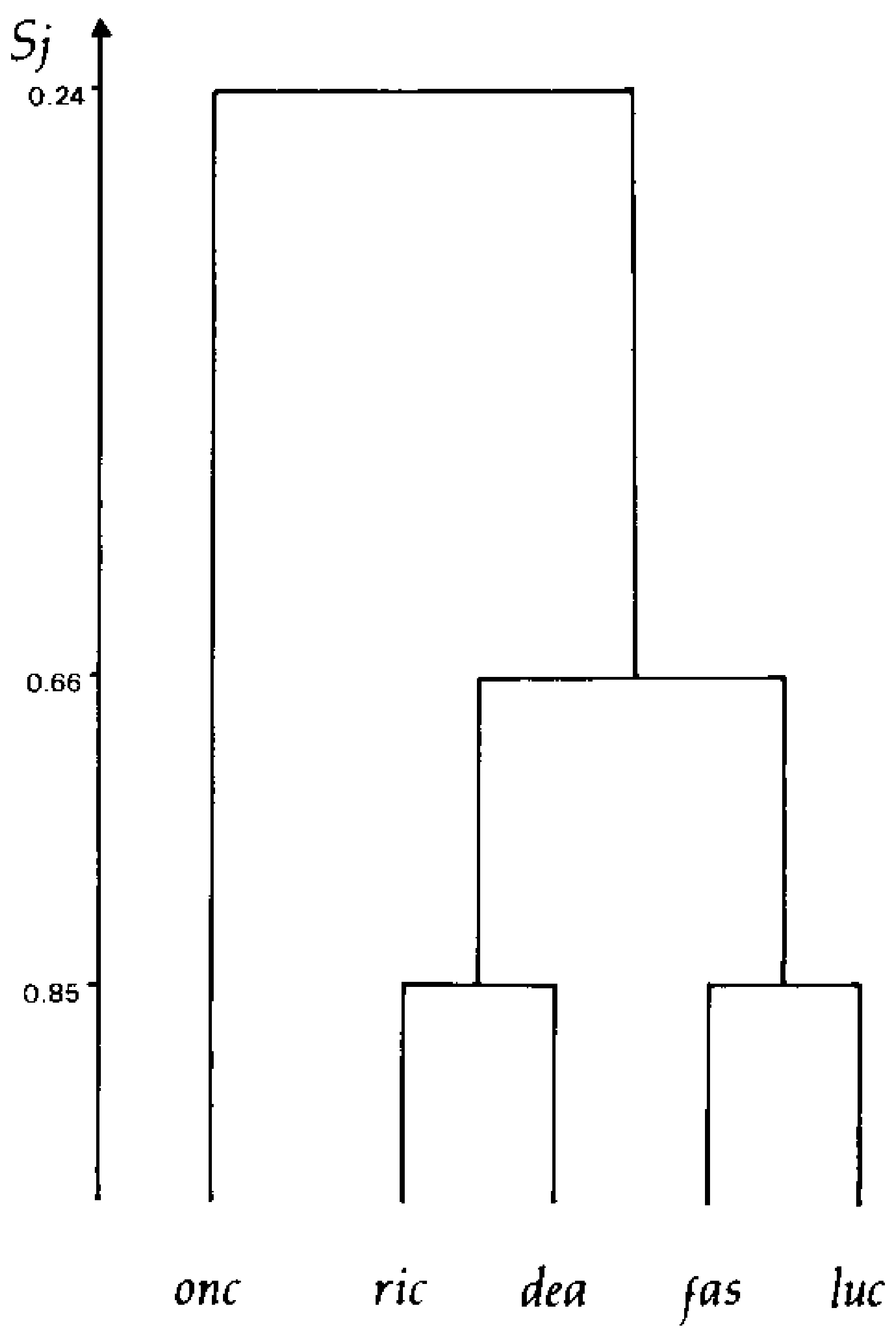

Fig. 4: dendogram showing groups wilh different Crithidia species. The isolates and the clones are identical in $C$. ricardoi. That new species is by morphology more similar to $C$. fasciculata and $C$. luciliae but by isoenzymes dissimilar to them, grouped nearer to $C$. deanei. "S $\mathrm{j}^{\text {": }}$ Jaccard's Coefficient of similarity.

\section{CONCLUSION}

C. ricardoi $\mathrm{sp} . \mathrm{n}$. is a new species of the genus Crithidia named after Ricardo Lourençode Oliveira. It was isolated from $C$. saltanensis while this mosquito was being examined for oocysts and sporozoites of Plasmodium juxtanucleare. $C$. saltanensis is the natural vector of this plasmodium. C. ricardoi sp. n. abundantly parasitizes the gut, mainly the hindgut, of that mosquito species. It can be transmitted to saltanensis larvae by diluting cultured $C$. ricardoi in the water the larvae were being bred in. Crithidias could be observed in the larval digestive tract and also adults after some days.

Combined results from electron microscopy, isoenzymes and kDNA analysis indicate that this isolate of Crithidia is a new species.

\section{ACKNOWLEDGEMENTS}

To Márcia Gonçalves de Castro for identification of the mosquitoes collected; to Maria Goreti Rosa Freitas-Sibajev for critical reviewing the manuscript; to Neide Thomaz for encouragement on the subject.

\section{REFERENCES}

CARVALHO, A. L. M. \& DEANE, M. P., 1974. Trypanosomatidae isolated from Zelus leucogramus with a discussion on flagellates of insectivorous bugs. J. Protozool., 21: 5-8.

LOURENÇO-DE-OLIVEIRA, R. \& CASTRO, F. A., 1991. Culex saltanensis Dyar, 1928 - Natural vector of Plasmodium juxianucleare in Rio de Janeiro, Brazil. Mem. Inst. Oswaldo Cruz, 86: 87-94.

McGHEE, R. B. \& HANSON, W. L., 1968. Growth and reproduction of Leptomonas oncopelti in the milkweed bug Oncopeltus fasciatus. J. Protozool, 10 : 239-243.

McGHEE, R. B.; HANSON, W. L. \& SCHMITTER, S. $M ., 1969$. Isolation cloning and determination of biologic characteristics of five new species of Crithidia. J. Protozool., 16: 514-520.

MOMEN, H.; GRIMALDI JR.; PACHECO, R. S.; JAFFE, C. L.; McMAHON-PRATT, D. \& MARZOCHI, $M$. C. A., 1985. Brazilian Leishmania stocks phenotypically similar to Leishmania major. Am. J. Trop. Med. Hyg., 34: 1076-1084.

PACHECO, R. S.; GRIMALDI JR. G.; MOMEN, H. \& MOREL, C. M., 1990. Population heterogeneity among clones of New World Leishmania species. Parasitology, 100: 393-398.

SOARES, M.; BRAZIL, R P.; TANURI, A. \& DE SOUZA, W., 1986. Some uitrastructural aspects of Crithidia guilhermei sp. n. isolated from Phaenicia cuprina. Can. J. Zool, 64: 2837-2842.

SNEATH, P. H. A. \& SOKAL, R. R., 1973. Numerical Taxonomy. San Francisco. Freeman. 573 p.

WALLACE, F. G., 1966. The trypanosomatidae parasites of insects and arachnids. Exper. Parasitology, I8: 124-193. 